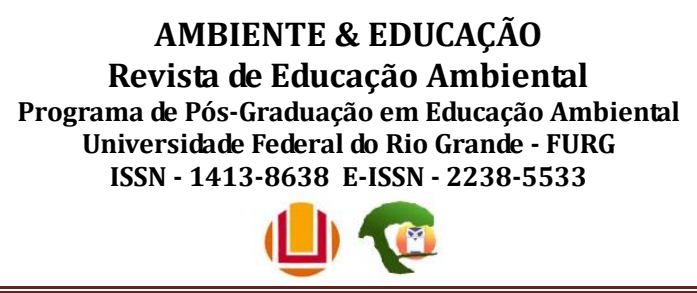

Dossiê Temático Educação Ambiental Não Formal

Vol. 22, n. 1, 2017.

\title{
RESTAURANDO A PAISAGEM: UM DESAFIO SOCIAL E AMBIENTAL ${ }^{1}$
}

Aline Beatriz Pacheco Carvalho ${ }^{2}$, Letícia Camacho Escobar ${ }^{3}$, Cristina Vargas Cademartori ${ }^{4}$

\section{RESUMO}

Considerando-se a perspectiva do diálogo sobre as relações entre a sociedade humana e a conservação da natureza, este trabalho tem por objetivo apresentar um estudo de caso que visou restaurar ecologicamente uma área degradada e promover, concomitantemente, ações de educação ambiental no âmbito não formal. A área, localizada no município de Glorinha-RS, é composta por uma paisagem formada por remanescentes de dois biomas típicos e ameaçados do Rio Grande do Sul, a Mata Atlântica e o Pampa. Motivados pelo dever ético-moral e preocupados com as situações adversas observadas, os proprietários permitiram que a área se tornasse objeto de estudo de um projeto de restauração e educação ambiental realizado entre os anos de 2013 a 2015.

Palavras-chave: conservação ambiental; educação ambiental; Mata Atlântica; restauração ecológica; impactos ambientais.

\begin{abstract}
Considering the dialogue perspective on the relationship between human society and nature conservation, this work aims to present a case study that aimed to restore ecologically degraded area and promote concurrently, environmental education in non-formal context . The area, located in the municipality of Glorinha-RS, is composed of a landscape formed by remnants of two typical biomes and threatened the Rio Grande do Sul, the Atlantic Forest and Pampa. Motivated by ethical and moral duty and concerned about the adverse situations observed, the owners allowed the area to become an object of study of a restoration project and environmental education conducted between 2013-2015.
\end{abstract}

Keywords: environmental conservation; environmental education; Atlantic forest; ecological restoration; environmental impacts.

\footnotetext{
1 Este trabalho foi previamente apresentado no formato de resumo expandido no IV Jornadas Mercosul, em Canoas. Esta versão foi ampliada e atualizada a partir das discussões promovidas no evento em questão.

2Bióloga, mestre em diversidade e conservação de fauna e doutoranda do PPG em Memória Social e Bens Culturais.

3Bióloga, mestranda do Curso de Mestrado em Avaliação de Impactos Ambientais - Centro Universitário La Salle - Unilasalle. Canoas, Rio Grande do Sul, Brasil.

4Bióloga, doutora e docente do PPG em Memória Social e Bens Culturais e do Mestrado em Avaliação de Impactos Ambientais.
} 


\section{INTRODUÇÃO}

Algumas áreas das ciências têm se preocupado em restaurar ecossistemas em oposição à mera exploração de recursos. Tal preocupação faz-se presente por meio de iniciativas em diversas localidades distribuídas pelo território nacional e tem aumentado o seu valor conforme crescem os impactos sobre o meio ambiente. Os princípios da ecologia da restauração buscam o restabelecimento de processos ecológicos em paisagens naturais ou urbanas, daí sua importância nos projetos socioambientais (RODRIGUES, 2013). Os projetos de restauração ecológica promovem a interação entre os atores envolvidos com a natureza e, ainda, colaboram para a mudança na relação meramente exploratória entre as pessoas e os ambientes em que vivem (HIGGS, 1997). Restaurações ecológicas têm valor significativo se estiverem inseridas em locais onde a comunidade do entorno possa ser integrada como agente participativo e torne-se multiplicadora de ações da mesma natureza (RODRIGUES, 2013). A promoção da reflexão a partir de ações focadas na melhoria e/ou remediação de problemas ambientais fundamenta a educação para o ambiente. Neste contexto, o resultado esperado da educação deve superar a compreensão de conceitos relativos à restauração. Deve, portanto, criar as condições necessárias para que as pessoas possam usar suas habilidades participativas de interação, planejamento e organização de um ambiente no qual o meio social e a natureza sejam parceiros integrativos (PREISTER, 1997).

A educação ambiental preconiza a formação do cidadão para a reflexão critica e visa prepará-lo para uma ação social corretiva ou transformadora de forma a viabilizar o desenvolvimento sustentável das sociedades humanas. Fundamentalmente, é necessária uma educação que permita desvelar os sentidos da realidade, problematizando as interpretações das diferentes forças sociais existentes. Desta forma, essa prática educativa abrirá um campo de novas possibilidades no sentido do reposicionamento e compromisso dos sujeitos frente aos desafios sobre a problemática ambiental. Uma das maiores contribuições da educação ambiental estaria no fortalecimento de uma ética socioambiental, ao incorporar valores que permitam a construção de um modelo social sustentável (PELICIONI, 2005). Na medida em que a problemática ambiental mostra-se indissociável da social, os projetos direcionados à conservação e/ou restauração do 
ambiente devem, além da preocupação ecológica, atentar às necessidades humanas das comunidades locais. Alguns projetos de restauração ecológica obtiveram sucesso em seus objetivos quando conseguiram, de alguma forma, sensibilizar e envolver as pessoas na tentativa de resgatar as condições naturais perdidas (HIGGS, 1997). Os benefícios associados à restauração não se limitam à recuperação de processos ecológicos, uma vez que demandam, também, ações educativas, envolvendo a participação e a reflexão constantes de uma equipe multidisciplinar, voluntários e da sociedade para sua efetiva execução. Assim, a restauração de ambientes degradados pode refletir uma oportunidade de ascensão social, à medida que proporciona o resgate da condição humana e da cidadania, pois as situações de degradação ambiental geralmente estão associadas às de degradação social (HIGGS, 1997).

\section{O COMPROMISSO DE RESTAURAR}

$\mathrm{O}$ risco iminente de desaparecimento deveria justificar por um imperativo o compromisso de restaurar ecossistemas impactados e ameaçados. Duas correntes convergem para justificar a restauração. A corrente de McCauley (2006) afirma que se deve restaurar por motivos ético-morais, enquanto Cairns e Heckman (1996) defendem a restauração em razão dos serviços ambientais disponibilizados pela natureza (RODRIGUES, 2013). Pesquisadores têm se mostrado sensíveis a estas justificativas e, além disso, fundamentam seus projetos em dispositivos legais que obrigam a restauração em inúmeras circunstâncias.

Os remanescentes da Mata Atlântica estão fragmentados e não se distribuem uniformemente ao longo do território, o que compromete a perpetuidade de espécies, da flora e fauna, consideradas raras ou não, endêmicas e ameaçadas de extinção. Além disso, a população humana também sofre as consequências dessa destruição, pois os serviços ambientais proporcionados pela Mata Atlântica estão associados à regulação do fluxo dos mananciais hídricos, à fertilidade do solo e ao equilíbrio climático. Igualmente importante é a preservação da paisagem da Mata Atlântica como patrimônio histórico e cultural, uma vez que expressa a memória e a cultura de diferentes grupos sociais, frutos da interação ser humano-natureza. 
O cenário de degradação da Mata Atlântica evidencia a urgência da restauração dos seus remanescentes frente a motivos ético-morais, à obrigatoriedade legal, às ameaças a sua biodiversidade e pela relevância para a promoção do desenvolvimento sustentável. Concomitantemente às aplicações técnicas do processo de restauração, são fundamentais práticas educativas que possibilitem o envolvimento e a formação de cidadãos comprometidos com a conservação da natureza.

Considerando as premissas expostas, este trabalho tem como objetivo relatar algumas ações resultantes de um projeto de restauração ecológica que visou incorporar a educação ambiental em suas práticas, desenvolvido em uma área degradada do domínio da Mata Atlântica no município de Glorinha, Rio Grande do Sul.

\section{O LOCAL DE ESTUDO}

O município de Glorinha, RS, possui cerca de 90\% de seu território ocupado por uma unidade de conservação de uso sustentável, a Área de Proteção Ambiental conhecida como APA do Banhado Grande. Criada em 1998 por Decreto Estadual, a APA do Banhado Grande possui 133.000 hectares formados pelos biomas Mata Atlântica e Pampa. A APA está situada nos municípios de Glorinha, Gravataí, Santo Antônio da Patrulha e Viamão. Os principais objetivos da APA são a preservação do conjunto de banhados, a compatibilização do desenvolvimento socioeconômico com a proteção dos ecossistemas naturais, a conservação do solo e recursos hídricos, a recuperação das áreas degradadas e a proteção da flora e fauna nativas, assim como de seus locais de reprodução (GLORINHA, RS s/a).

A problemática das relações entre a população humana, a paisagem e os recursos naturais é considerada central nas discussões sobre o uso e o gerenciamento do território, e a conservação da natureza em unidades de conservação. Assim como em outros lugares do Estado, o município de Glorinha enfrenta o desafio de conciliar interesses e necessidades da população com a urgência de conservar os remanescentes naturais presentes nos limites do município.

\section{RESTAURAR É PRECISO: UM ESTUDO DE CASO}


A área de estudo possui cerca de 3,5 hectares e está situada no município de Glorinha, sob o domínio da APA do Banhado Grande. A paisagem é formada por um misto de remanescentes de dois biomas típicos e ameaçados do Rio Grande do Sul, a Mata Atlântica e o Pampa. Anteriormente ao ano de 2008, a área era utilizada para pastoreio, criação de bovinos e plantio de cítricos sem fins comerciais. Dentre os impactos decorrentes destas atividades estavam a caça de animais silvestres, supressão da vegetação para a ampliação da área de cultivo, um remanescente florestal com o subbosque pouco desenvolvido, ocorrência de gramíneas e espécies arbóreas exóticas, compactação do solo e de áreas úmidas presentes na propriedade. Após a aquisição da área pelos atuais proprietários, as atividades de impacto ao ambiente cessaram e pôde-se observar o processo natural de sucessão ecológica ${ }^{5}$. Porém, tal processo exigiu intervenção técnica, já que apenas os processos naturais não produziriam o êxito esperado. A melhor hipótese para essa afirmativa era a de que o solo se apresentava exaurido e ocupado por gramíneas exóticas, além de a área estar distante de fontes de propágulos (figura 1). Desta forma, motivados pelo dever ético-moral e preocupados com as situações adversas observadas, os proprietários permitiram que a área se tornasse objeto de estudo de um projeto de restauração realizado entre os anos de 2013 a 2015.

Durante o primeiro ano, as atividades concentraram-se em torno do diagnóstico sobre os principais agentes de perturbação da área, bem como da proposição de soluções exequíveis em um período de ação determinado (tabela 1). Concomitantemente aos inventários faunísticos e floristicos, foram definidas as técnicas e as atividades de educação ambiental que seriam empregadas, considerando-se os seus respectivos propósitos e a relação com os impactos observados (tabela 2).

5 Refere-se à sequência de comunidades vegetais, animais e microorganismos que sucessivamente ocupam uma área ao longo do tempo ou aos processos de mudanças que essas comunidades bióticas imprimem umas às outras, ocasionando mudanças nas condições físicas do meio ambiente (KIMMINS; MAILLY, 1996). 


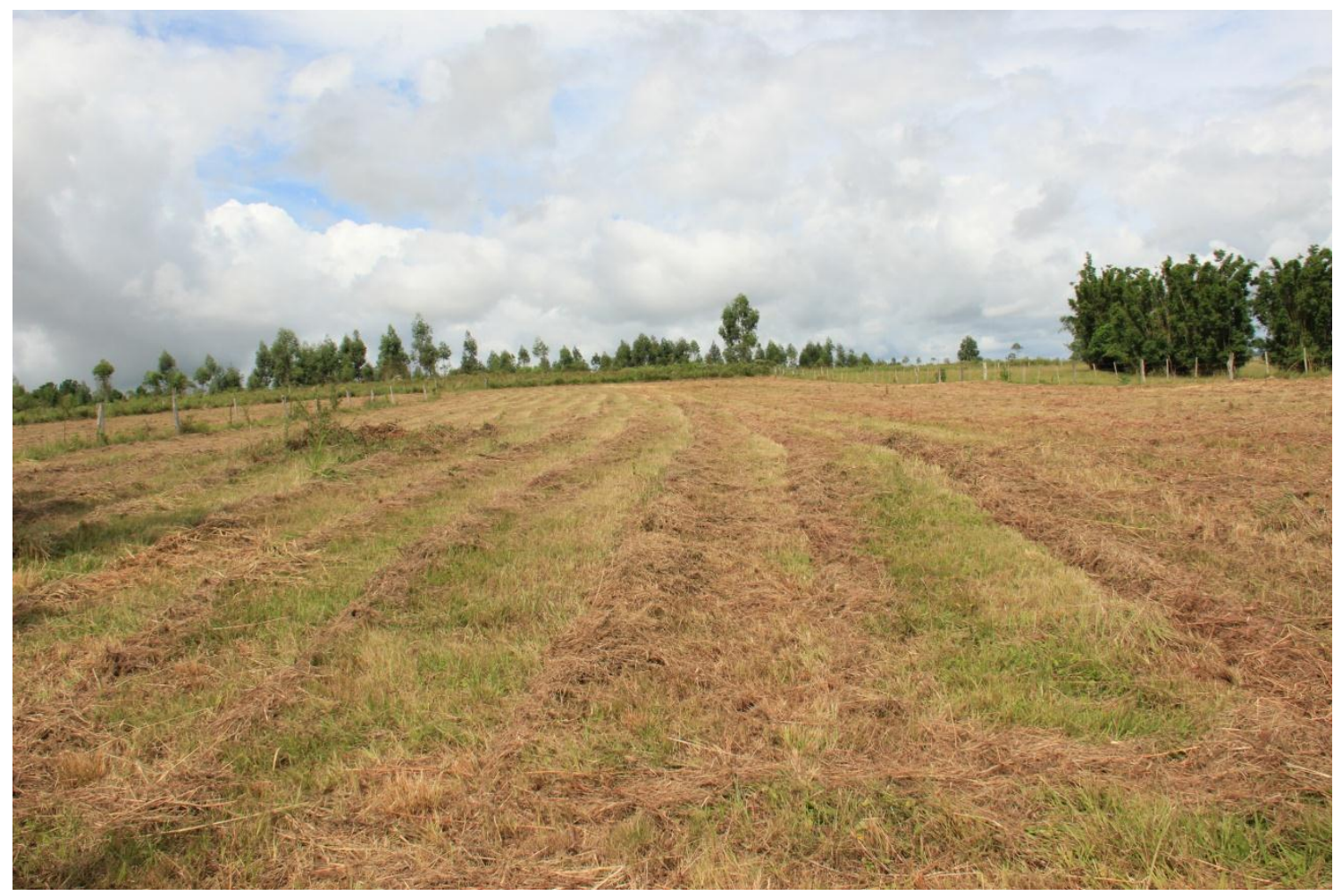

Figura 1. Cobertura do solo da área de estudo, localizada no município de Glorinha, RS, evidenciando a presença de gramíneas exóticas.

Tabela 1. Identificação dos agentes de perturbação e as propostas de intervenção realizadas entre os anos de 2013 e 2015 em área degradada do município de Glorinha, RS.

\section{AGENTES DE PERTURBAĈ̃O PROPOSTAS}

Presença de espécies vegetais exóticas.

Efeito de borda em remanescente de mata ciliar.

Solo desnudo e assoreado.

Pastejo e pisoteio do gado em banhado, subbosque e nascentes.

Supressão vegetal clandestina.

Caça clandestina.
Remoção mecânica sem o uso de substâncias químicas.

Isolamento da área e enriquecimento através de plantio direto de mudas nativas.

Isolamento da área. Poleiros e atrativos para a fauna dispersora de sementes.

Isolamento da área.

Educação Ambiental. Intervenção direta com a comunidade vizinha.

Educação Ambiental. Intervenção direta com a comunidade vizinha e visitantes externos oriundos da educação básica e ensino superior. 
Tabela 2. Técnicas de restauração utilizadas durante os anos de 2014 a 2015 em área degradada do município de Glorinha, RS.

\begin{tabular}{ll}
\hline TÉCNICAS DE RESTAURAÇÃO & PROPÓSITO \\
\hline $\begin{array}{l}\text { Isolamento das áreas de preservação } \\
\text { permanente (APP). }\end{array}$ & Evitar o pisoteio e pastejo do gado. \\
Semeadura e plantio de mudas nativas. & $\begin{array}{l}\text { Facilitar o restabelecimento e enriquecer a comunidade } \\
\text { vegetal; aumentar a disponibilidade de recursos para a } \\
\text { fauna. }\end{array}$ \\
$\begin{array}{ll}\text { Abrigos horizontais formados por entulhos e } \\
\text { dispostos no solo. }\end{array}$ & $\begin{array}{l}\text { Servir de atrativo/abrigo para animais dispersores de } \\
\text { sementes. }\end{array}$ \\
Poleiros. & $\begin{array}{l}\text { Servir de atrativo/descanso para aves dispersoras de } \\
\text { sementes. }\end{array}$ \\
Educação Ambiental & $\begin{array}{l}\text { Ampliar e incentivar o diálogo ambiental; salientar os } \\
\text { pontos positivos da restauração e suscitar a participação } \\
\text { do coletivo através de ações que coíbam a invasão da } \\
\text { área do projeto para a caça e a depredação; proporcionar } \\
\text { atividades de educação sensibilização ambiental a } \\
\text { visitantes externos oriundos da educação básica e ensino } \\
\text { superior. }\end{array}$ \\
\hline
\end{tabular}

Inúmeras razões justificam a implantação de programas que priorizam a conservação e a restauração ecológica de biomas ameaçados. Nossa tentativa de restaurar um fragmento de Mata Atlântica vislumbrou, como um dos resultados a serem alcançados, a formação de uma área de conexão entre fragmentos próximos que pudesse atuar como um corredor ecológico ou servir como local de repouso, abrigo e fonte de alimento para a fauna. As restaurações proporcionam o aumento da riqueza florística e faunística locais, trazendo, como consequência, diversos benefícios e serviços ambientais. Além de promover melhora da saúde humana e da qualidade de vida, contribui para o aumento da diversidade genética, garantindo e protegendo a integridade da vida (NATIONAL RESEARCH COUNCIL, 1992; DAVIS, 2004; SER, 2004). Os esforços em prol da restauração ecológica são positivos, pois proporcionam o reparo, em ecossistemas degradados, de uma ou mais condições próximas ao estado original. Desta forma, possibilitam a recolonização e o restabelecimento da fauna e da flora no local restaurado. Este projeto, portanto, visou implementar ações favoráveis ao aumento da diversidade e ao restabelecimento de condições próximas às originais, que pudessem assegurar os atributos e valores ecológicos de ecossistemas pertencentes ao domínio da 
Mata Atlântica. Associados a estes objetivos, buscou-se planejar atividades de educação ambiental inspiradas, inicialmente, nas temáticas alfabetização ecológica de Fritjof Capra (STONE, 2006) e pedagogia da terra (GADOTTI, 2013). No intuito de compartilhar experiências e inspirar ações semelhantes, tomou-se a iniciativa de convidar e receber, na área do projeto, grupos organizados provenientes de escolas de ensino fundamental e de cursos de graduação em Ciências Biológicas de Porto Alegre, RS. Os relatos e ensaios a seguir sintetizam os resultados obtidos durante os dois anos de experiências integradas ao projeto.

\section{ALGUMAS IMPLICAÇÕES PARA A EDUCAÇÃO}

Restaurações ecológicas podem colaborar para a mudança nas relações utilitaristas que as pessoas estabelecem com o meio ambiente e, nesse caso, é mais importante perceber como as pessoas interagem com a restauração do que o produto final desse processo (HIGGS, 1997). Este projeto visou compartilhar algumas experiências com alunos das séries iniciais e do ensino superior com o propósito de que, por meio de suas vivências e interpretações, passassem a valorizar a natureza, sua reabilitação e, assim, apoiassem e/ou participassem de projetos semelhantes em outros locais. Em nossas ações, procuramos criar condições para o desenvolvimento de postura crítica e participativa, e da habilidade de propor ações preditivas, que propiciassem cuidados a um ambiente fragilizado, impactado ou em processo de restauração. Três questões principais nortearam o planejamento das atividades de educação ambiental: a restauração da paisagem, promovendo o incremento da biodiversidade; a sensibilização em relação à fauna e flora ameaçadas do Estado do Rio Grande do Sul; e o papel do ser humano como provedor e mediador de estratégias e ações em benefício da conservação do meio ambiente. A escolha das questões norteadoras se deu a partir do consenso de que seriam de interesse à formação ecológica dos envolvidos, considerando desde os organizadores do projeto aos alunos de ensino fundamental e acadêmicos de Ciências Biológicas.

\section{OS RESULTADOS ALCANÇADOS}


Ao longo de dois anos foram realizadas visitações orientadas ao público da educação básica e superior, envolvendo cerca de 200 visitantes, interessados em vivenciar experiências práticas sobre a temática ambiental (figura 2). Após o primeiro ano de atividades de restauração, algumas modificações na paisagem tornaram-se evidentes, trazendo resultados positivos. A recuperação do solo, das nascentes e do banhado somouse a outras respostas desencadeadas por estas (figura 3). $\mathrm{O}$ incremento da vegetação e a continuidade do processo de sucessão ecológica resultaram em maior diversidade de espécies vegetais e novas oportunidades para a fauna local e visitante, que passaram a utilizar as áreas vegetadas como fonte de abrigo e alimentação. Tais resultados possibilitaram o planejamento de algumas atividades:

\section{Plantio de Mudas}

Ponderando que restaurar é mais que plantar árvores, Efraim Rodrigues, 2013 considera que as crianças, sozinhas, não conseguem interpretar a experiência de plantar sem que haja a condução e orientação adequada para tal atividade. Portanto, a experiência isolada sem a devida contextualização corre o risco de se esvaziar, à medida que os sujeitos encontram um cenário pronto para o plantio das mudas, que se configura na sua única participação ao longo de todo o processo (RODRIGUES, 2013). A preparação e a condução da atividade devem, então, perpassar os objetivos e as justificativas que fundamentaram o convite para o plantio, de modo que a colocação das mudas nas covas seja o resultado significativo de uma ação maior e mais abrangente.

A atividade de plantio, uma das etapas do projeto, envolveu, em momentos diferentes, alunos do ensino básico, na faixa etária de 9 a 12 anos, e alunos do ensino superior com idades entre 18 e 25 anos. O intuito foi contribuir para a restauração da mata ciliar remanescente na propriedade e sensibilizar os participantes para as questões que envolvem a conservação e a restauração de áreas florestadas. Esta ação foi conduzida através de uma aula expositiva e dialogada, e finalizada com a prática do plantio. A contextualização do problema baseou-se na exploração dos recursos naturais, na flora ameaçada do Rio Grande do Sul e na substituição de áreas vegetadas por áreas cultivadas. Os alunos tiveram, ainda, a oportunidade de conhecer um viveiro de mudas, bem como 
refletir sobre a importância de reflorestar priorizando mudas de espécies nativas. Cada participante escolheu uma muda e promoveu o seu plantio. Cada muda, por sua vez, foi identificada com uma placa contendo o nome da respectiva espécie, o nome do aluno e a data do plantio. Ao final da atividade todos foram convidados para retornar ao local a fim de acompanhar o crescimento das mudas escolhidas. Com essa iniciativa se pretendeu sensibilizar os envolvidos e incentivá-los a observar e zelar pela dinâmica sistêmica da vida.

\section{Observando a Sucessão Ecológica}

Em projetos de restauração ecológica, espera-se que em determinado momento, a área tenha condições físicas e químicas de sustentar a comunidade que está sendo restaurada. Espera-se ainda, que, ao passar das etapas físicas e químicas para a biológica, a restauração sofrerá um acréscimo de complexidade de seus componentes bióticos e abióticos através do processo de sucessão (RODRIGUES, 2013). As atividades educativas associadas à observação da sucessão ecológica podem favorecer a compreensão sobre o papel da diversidade biológica na estruturação dos sistemas vivos.

Em uma das atividades, esses conceitos ecológicos, por vezes complexos, foram abordados com turmas de educação básica e exemplificados a partir da observação de uma área de monocultura abandonada na propriedade, que anteriormente havia sido atingida por insetos pragas de milho. Tal área apresentava-se, na época, em estágio inicial de sucessão ecológica. Ao observar tal situação foi possível promover a reflexão sobre a disponibilidade de recursos como prioridade para o estabelecimento de espécies mais tolerantes, em detrimento das menos tolerantes e, portanto, mais sensíveis ou seletivas. Ao final da atividade, as discussões entre os presentes versaram sobre os processos ecológicos relativos às mudanças físicas e químicas que uma área pode sofrer, e às diferentes espécies que nela podem se estabelecer ao longo do tempo, através do modelo sucessional de facilitação, no qual cada espécie facilita ou não o estabelecimento da próxima (RODRIGUES, 2013; GOTELLI, 2005). Pretendeu-se, desta forma, suscitar a reflexão e o diálogo sobre a importância do processo de sucessão ecológica em fisionomias terrestres de áreas degradadas em processo de restauração. 
ISSN- 1413-8638

E-ISSN - 2238-5533

v. 22, n. 1, p. 132-145, 2017

\section{Observação da Fauna}

O aumento da riqueza faunística foi evidenciado pelos inventários sistemáticos realizados sazonalmente, o que propiciou o desenvolvimento de atividades educativas relacionadas à observação dos animais através de seus vestígios (penas caídas no solo, pegadas, tocas, fezes, vocalizações) e do contato visual direto (atividade de observação da avifauna). A prática de observação de animais estimula o diálogo conservacionista e incentiva a adoção de valores e compromissos morais, éticos e legais vinculados à promoção do bem-estar animal e à conservação das áreas verdes como recursos prioritários à manutenção da vida silvestre e da diversidade biológica (FIGURA 4).

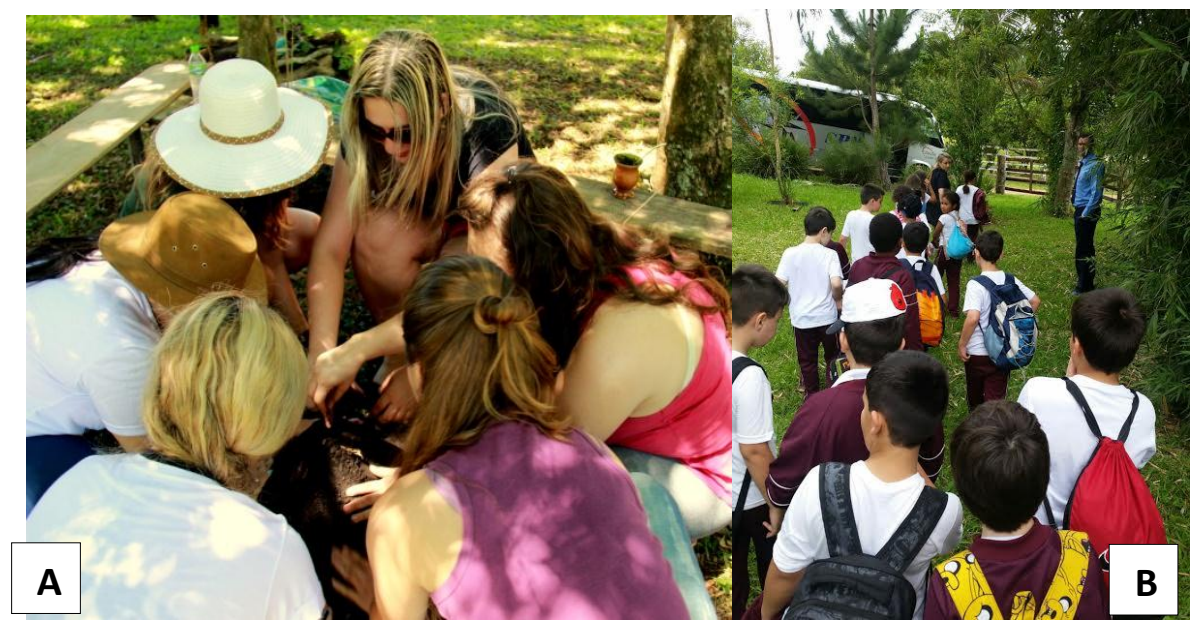

Figura 2. A - Primeira turma de acadêmicos de Ciências Biológicas a participar de uma ação de educação ambiental promovida pelo projeto; $\mathbf{B}$ - primeira turma de ensino básico a participar da visitação orientada na sede do projeto, em Glorinha, RS.

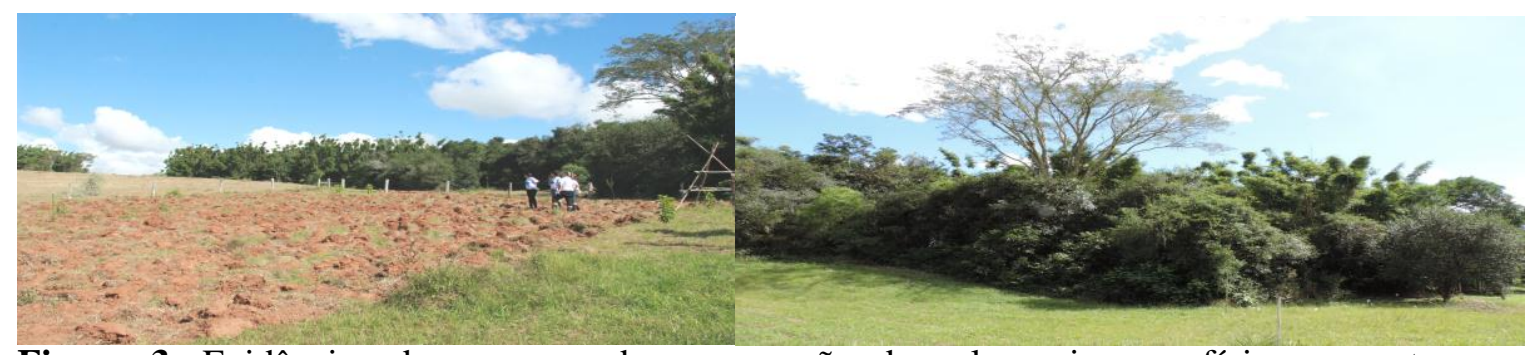

Figura 3. Evidências do processo de recuperação do solo, cuja superfície apresentava-se descoberta no ano de 2013 e em 2015, já com cobertura de gramíneas. 


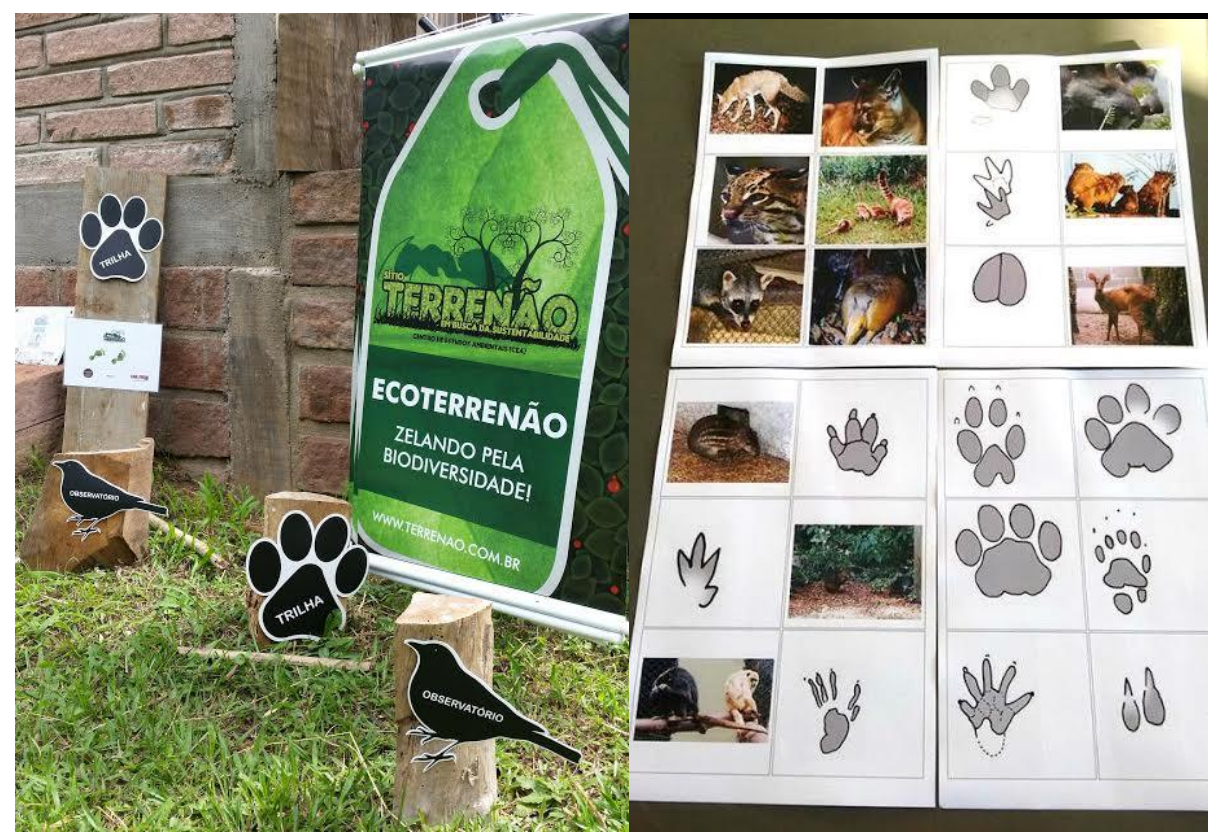

Figura 4: Materiais didáticos utilizados nas atividades relacionadas à observação dos animais através de seus vestígios (pegadas) e do contato visual direto (observação da avifauna).

\section{PERSPECTIVAS FUTURAS}

A proposição de atividades que não ressaltem apenas os problemas ambientais e apresentem possibilidades de interação e compreensão dos processos naturais, contribuem para a alfabetização ecológica e criam espaço para o desenvolvimento de uma postura de admiração e contemplação que o mundo natural é capaz de evocar (MICHAEL, 2006). Deve-se, portanto, incorporar nas atividades educativas as diversas formas de interação com o meio natural, que possibilitem a formação de sujeitos ecológicos, críticos e capazes de refletir sobre os problemas ambientais em prol de uma cidadania ambiental. A educação ambiental, consequentemente, constitui-se em importante processo de transformação social para a constituição de sociedades mais justas, ecologicamente sustentáveis e compromissadas com a conservação dos processos que garantem a integridade dos sistemas ecológicos.

Orr (2006) enfatiza que a crise ambiental é, em todos os sentidos, uma crise da educação. Consequentemente, toda educação é educação ambiental e deve ser capaz de ensinar que somos parte integrante e apenas um elo do mundo natural. Mais do que o domínio de matérias especificas do conhecimento, a Pós-modernidade exige pessoas 
ecologicamente alfabetizadas, que compreendam as complexas relações entre os seres vivos e o seu entorno, e reconheçam que, enquanto espécie, somos uma parte inextricável da comunidade do planeta.

A complexidade da restauração de ecossistemas, aliada aos diferentes tempos de resposta dos processos e dos organismos envolvidos, exige acompanhamento, monitoramento e manutenção ininterruptos. Analogamente, a complexidade das questões intrínsecas ao processo educativo e o respeito pelos distintos tempos de resposta dos sujeitos envolvidos impõem aos projetos de educação ambiental a necessidade de execução contínua. Com esta perspectiva, as próximas etapas deste projeto buscarão o envolvimento da comunidade escolar local a partir de suas múltiplas percepções acerca do patrimônio natural da região. Para tanto, pretende-se consolidar, na área sede do projeto, um Centro de Estudos Ambientais, e firmar parcerias com instituições de ensino da rede básica e superior (Graduação, Lato e Stricto Sensu) para incorporar sistematicamente atividades de ensino, pesquisa e extensão, assim como trabalhos de integração socioambiental que contribuam para a educação ambiental e, através da restauração, para a conservação da Mata Atlântica.

\section{REFERÊNCIAS}

BENSUSAN, Nurit. Conservação da Biodiversidade em áreas protegidas. Editora: FGV, Rio de Janeiro. 176 pg. 2006.

CAIRNS, Jonh Jr. e HECKMAN, Jonh R. Restoration Ecology: The State of na emerging Field. Annual Review of Energy and Environment 21:167-89. 1996.

CAPRA, Fritjof. Falando a linguagem da natureza: princípios da sustentabilidade in Stone, M. K., Barlow, Z. Alfabetização ecológica: a educação das crianças para um mundo sustentável. São Paulo: Cultrix. p. 48-49. 2006.

DAVIS, Mark e SLOBODKIN, Lawrence. The Science and Values of Restoration Ecology. Restoration Ecology. 12:1-3. 2004.

GADOTTI, Moacir. Pedagogia da Terra. São Paulo: Peirópolis. p. 210-212. 2000.

GLORINHA, RS. Disponível em: http://www.glorinha.rs.gov.br/glorinha_rs/index.php?option=com_content\&view=article\&id=56 \&Itemid=64> . Acesso em: 12 de agosto de 2016.

GOTELLI, Nicholas. Ecologia. Editora Planta. p. 60-66. 2007.

HIGGS, Eric. What is good ecological restoration? Conservation Biology. 11:338-48. 1997.

ORR, David. W. Prólogo in Stone, M. K., Barlow, Z. Alfabetização ecológica: a educação das crianças para um mundo sustentável. São Paulo: Cultrix. p. 9-12. 2006.

McCAULEY, Douglas. Selling out on nature. Nature 443:27-8. 2006. 
MICHAEL, Pamela. Ajudando as crianças a se apaixonar pelo planeta Terra: educação ambiental e artística in Stone, M. K., Barlow, Z. Alfabetização ecológica: a educação das crianças para um mundo sustentável. São Paulo: Cultrix. p. 144-146. 2006.

MMA. Ministério do meio ambiente. Secretaria de Biodiversidade e florestas. Núcleo Mata Atlântica e Pampa. Mata Atlântica: patrimônio nacional dos brasileiros /; organizadores Maura Campanili [e] Wigold Bertoldo Schaffer. - Brasília: MMA, p. 135-144. 2010.

NATIONAL RESEARCH COUNCIL. Restoration of Aquatic Ecosystems: Science, Tecnology, And Public Policy Natl. ACAD. PRESS. p. 501-506. 1992.

PELICIONI, Maria. Cecilia Focesi e PHILIPPI, Arlindo. Jr. Bases políticas, conceituais, filosóficas e ideológicas da Educação Ambiental in Educação Ambiental e sustentabilidade. Pelicioni, M. C. F., Philippi, A. Jr. Barueri, SP: Manole. 2005.

PREISTER, Kevin e KENT, James. Social Ecology: A new pathway to watershed restoration in Watershed Restoration: Principles and practices. Williams J. E, Wood, C.A, Dombeck, M.P. American Fisheries Society. 1997.

RODRIGUES, Efraim. Ecologia da Restauração. Editora Planta, Londrina. 2013.

SER SCIENCE AND POLICY WORING GROUP. The Ser Primer on Ecological Restoration. 2004.

STONE, Michael K. e BARLOW, Zenobia. Alfabetização ecológica: a educação das crianças para um mundo sustentável. São Paulo: Cultrix. p. 27. 2006.

KIMMINS, James P. e MAILLY, Daniel. Ecological succession: processes of change in ecosystem in: Kimmins, J.P. (Ed.). Forest Ecology. New York: Macmillan Publishing Company. p. 399-348. 1996. 